\title{
Single Cavernous Hemangioma of the Small Bowel Diagnosed by Using Capsule Endoscopy in a Child with Chronic Iron-Deficiency Anemia
}

\author{
Soo Jin Bae ${ }^{1}$, Geol Hwang ${ }^{1}$, Hyun Sik Kang ${ }^{1}$, Hyun Joo Song ${ }^{2}$, Weon Young Chang ${ }^{3}$, Young Hee Maeng ${ }^{4}$ and Ki-Soo Kang ${ }^{1}$ \\ Departments of Pediatrics ${ }^{1}$, Internal Medicine ${ }^{2}$, Surgery ${ }^{3}$, and Pathology ${ }^{4}$, Jeju National University College of Medicine, Jeju, Korea
}

Cavernous hemangiomas of the gastrointestinal tract are extremely rare. In particular, the diagnosis of small bowel hemangiomas is very difficult in children. A 13-year-old boy presented at the outpatient clinic with dizziness and fatigue. The patient was previously diagnosed with iron-deficiency anemia at 3 years of age and had been treated with iron supplements continuously and pure red cell transfusion intermittently. Laboratory tests indicated that the patient currently had iron-deficiency anemia. There was no evidence of gross bleeding, such as hematemesis or bloody stool. Laboratory findings indicated no bleeding tendency. Gastroduodenoscopy and colonoscopy results were negative. To obtain a definitive diagnosis, the patient underwent capsule endoscopy. A purplish stalked mass was found in the jejunum, and the mass was excised successfully. We report of a 13-year-old boy who presented with severe and recurrent iron-deficiency anemia caused by a cavernous hemangioma in the small bowel without symptoms of gastrointestinal bleeding. Clin Endosc 2015;48:340-344

Key Words: Anemia, iron-deficiency; Hemangioma, cavernous; Capsule endoscopy; Child

\section{INTRODUCTION}

Cavernous hemangiomas in the gastrointestinal (GI) tract are rare in children. ${ }^{1-4}$ These tumors are usually asymptomatic for a long time, often being diagnosed as an incidental finding or during investigative procedures for other disorders. ${ }^{3-7}$ Cavernous hemangiomas are mainly found in the upper and lower GI tract, and they rarely occur in the small intestine. ${ }^{1-4,8}$ The most common clinical presentation is GI bleeding; ${ }^{2}$ the major symptom of hemangioma of the small intestine is occult or overt GI bleeding.

The diagnosis of cavernous hemangiomas are usually made by using computed tomography (CT), magnetic resonance

Received: July 11, 2014 Revised: August 12, 2014

Accepted: December 8, 2014

Correspondence: Ki-Soo Kang

Department of Pediatrics, Jeju National University College of Medicine, 15 Aran 13-gil, Jeju 690-767, Korea

Tel: +82-64-754-8146, Fax: +82-64-754-3114, E-mail: kskang@jejunu.ac.kr

(cc) This is an Open Access article distributed under the terms of the Creative Commons Attribution Non-Commercial License (http://creativecommons.org/ licenses/by-nc/3.0) which permits unrestricted non-commercial use, distribution, and reproduction in any medium, provided the original work is properly cited. imaging (MRI), barium swallow study, double-balloon enteroscopy, or capsule endoscopy in patients with obscure or overt bleeding. ${ }^{2}$ The diagnosis is extremely difficult because small bowel hemangiomas are rarely demonstrable. Radiological methods show low accuracy in detecting the origin of a hemangioma in the small bowel. ${ }^{1}$ In recent years, capsule endoscopy has been used to diagnose small bowel lesions in patients with obscure and overt GI bleeding. ${ }^{3,9,10}$

In the domestic literature, there is only one report of a small bowel hemangioma in a child; ${ }^{11}$ in this previous report of a 2-year-old boy with severe iron-deficiency anemia and gross GI bleeding, a small bowel hemangioma was detected during an exploratory laparotomy. Herein, this is the first domestic report of a case of cavernous hemangioma of the small intestine diagnosed with capsule endoscopy with no evidence of gross GI bleeding.

\section{CASE REPORT}

A 13-year-old boy came to the hospital with symptoms of 

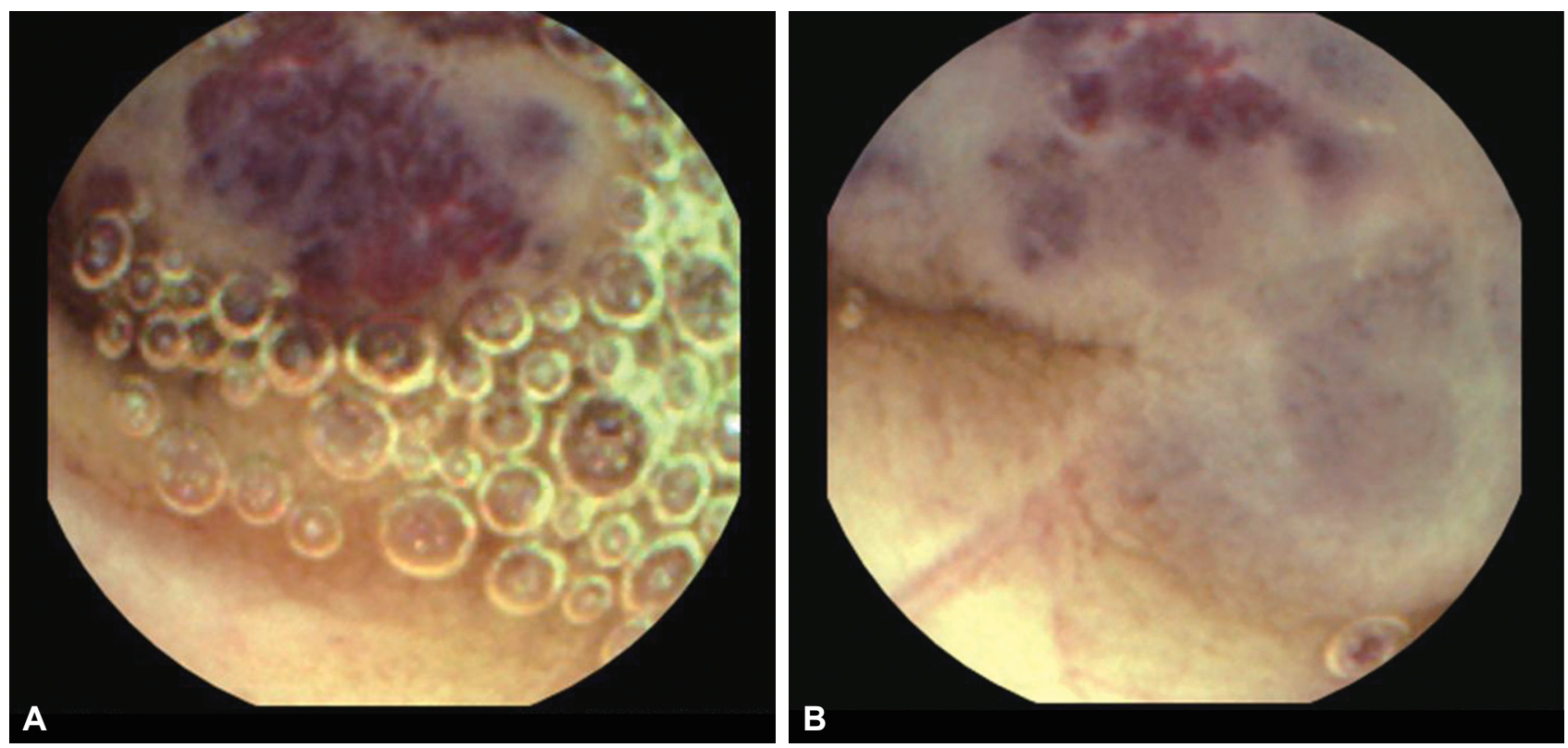

Fig. 1. (A, B) A purple-colored polypoid mass with surface bleeding in the jejunum was found by using capsule endoscopy.
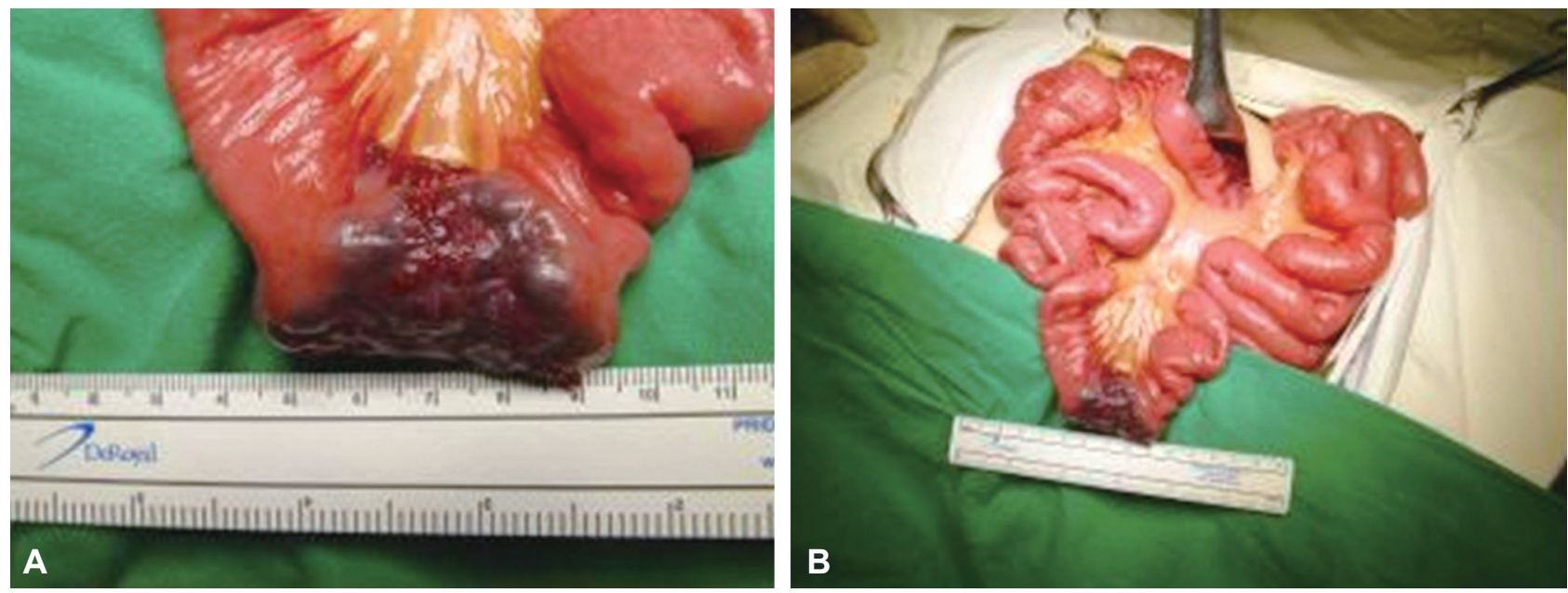

Fig. 2. (A, B) The resected segment of the ileum showed a mass, $4.2 \times 5.2 \mathrm{~cm}$ in size.

nausea and dizziness for a week. The patient had no symptoms of hematemesis or bloody stool. At the time of physical examination in the hospital, the patient was conscious and his conjunctiva was pale. The abdomen showed no distension, flank pain, masses, or organomegaly. There were no bleeding tendencies such as purpura, petechial rash, or skin bruising. The physical examination revealed no other specific signs.

An analysis of the patient's previous history revealed that recurrent episodes of severe iron-deficiency anemia had been treated with blood transfusion and iron supplements since the age of three years. These symptoms had improved transiently upon treatment. However, he had defaulted on subsequent follow-up.

A complete blood count showed an hemoglobin $(\mathrm{Hb})$ level of $6.6 \mathrm{~g} / \mathrm{dL}$, mean corpuscular volume of $73.9 \mathrm{fL}$, mean corpuscular hemoglobin of $21.5 \mathrm{pg}$, hematocrit of $22.7 \%$, white blood cell count of $5,400 / \mathrm{mm}^{3}$ with $87.9 \%$ neutrophils, and platelet count of $444,000 / \mathrm{mm}^{3}$. Urinalysis and a stool examination did not indicate blood loss. The analyses for iron-deficiency anemia showed ferritin levels of $3.1 \mathrm{ng} / \mathrm{mL}$, serum iron levels of $191 \mu \mathrm{g} /$ $\mathrm{dL}$, total iron-binding capacity of $342 \mu \mathrm{g} / \mathrm{dL}$, and transferrin levels of $295 \mathrm{mg} / \mathrm{dL}$. Results of gastroduodenoscopy, colonoscopy, and Meckel scans were negative. To obtain a definite diagnosis and find the obscure bleeding focus, the patient underwent capsule endoscopy. Capsule endoscopy showed a purple-colored polypoid mass with surface bleeding in the jejunum (Fig. 1).

At that point, obscure bleeding resulting in refractory iron-deficiency anemia could not be ruled out. Excision of the 


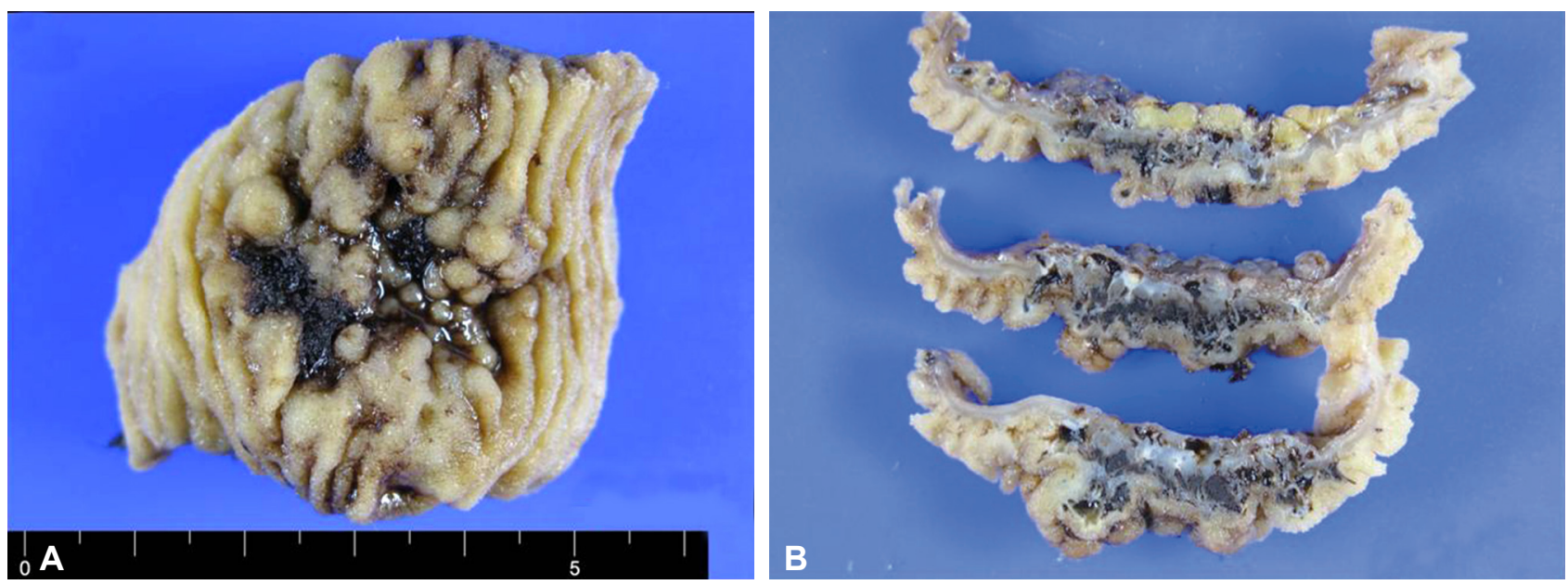

Fig. 3. Gross findings of the resected small intestine showed (A) an irregular ulceration with surface hemorrhage, and (B) spongy-like blood clot-filled spaces in the whole layer of the intestinal wall.
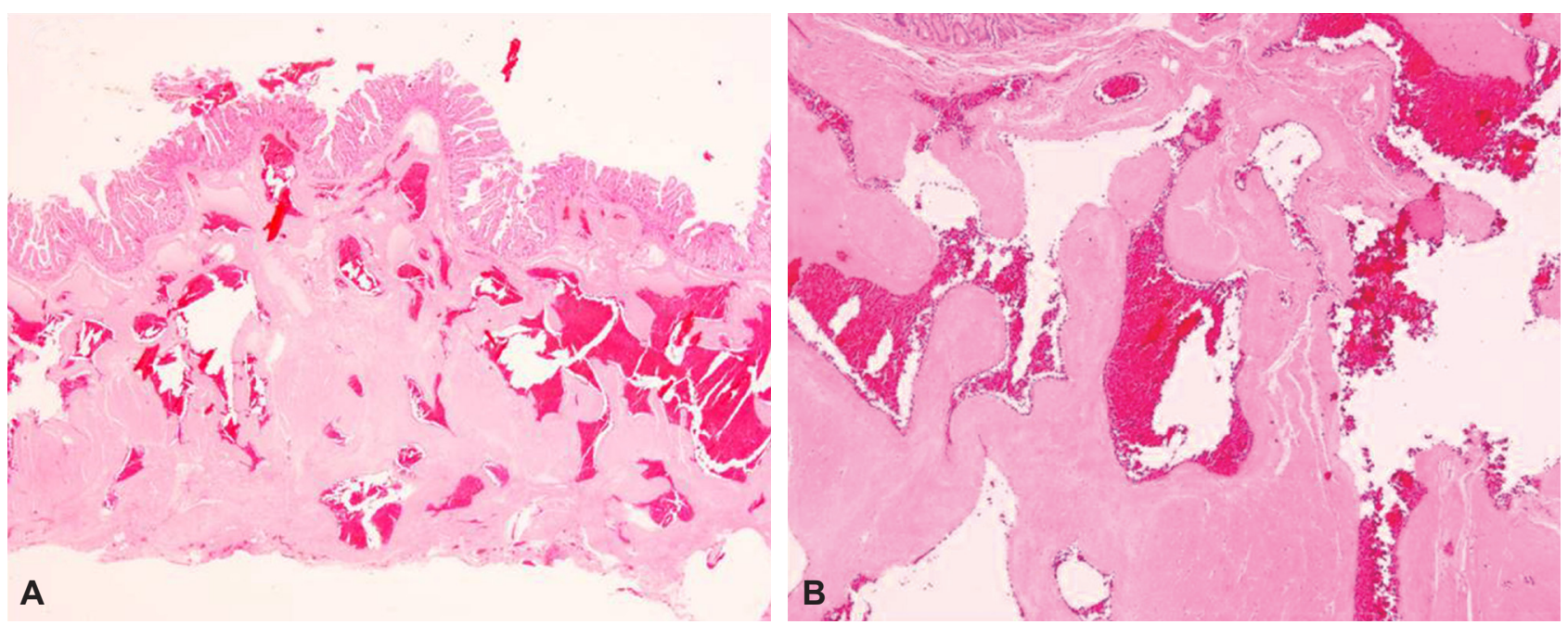

Fig. 4. Microphotographs of the lesion showed irregularly dilated vascular spaces in the submucosal and muscle layers $(A, H \& E$ stain, $\times 40)$ and blood-filled vascular structures lined by a single layer of endothelial cells ( $B$, H\&E stain, $\times 100)$.

mass, about $140 \mathrm{~cm}$ below the Treitz ligament, was performed successfully (Fig. 2). Macroscopically, the surgical specimen was a $4.2 \times 5.2-\mathrm{cm}$ hemangioma involving the entire layer of the intestinal wall, and it consisted of spongy-like spaces filled with blood clots (Fig. 3). Microscopically, the tumor consisted of irregular dilated, blood-filled vessels lined by flattened endothelium (Fig. 4). Histology indicated that the tumor was a cavernous hemangioma.

The patient was discharged 7 days postsurgery. During the 3 years of follow-up postsurgery, the patient was healthy and did not experience anemia. The patient's $\mathrm{Hb}$ level was $14.6 \mathrm{~g} / \mathrm{dL}$.

\section{DISCUSSION}

Hemangiomas in the small intestine are very rare benign tumors that account for approximately 5\% of all GI neoplasms. ${ }^{1,2}$ Typically, they occur in the ileum. ${ }^{4}$ The lesions are rarely found in children; only a few cases have been reported in the literature. The major symptom of hemangioma of the small intestine is overt GI bleeding. ${ }^{2}$ Less commonly, cavernous hemangioma in the small bowel may present with different chronic or obscure types of GI bleeding. ${ }^{4}$ Occasionally, an obstruction may be the initial finding.

Preoperative diagnosis is extremely difficult because small hemangiomas are rarely demonstrable. Traditional techniques to investigate the small intestine include CT, MRI, barium swallow study, double-balloon enteroscopy, or capsule endoscopy. ${ }^{2,12}$ However, these often lack accuracy. ${ }^{1,12,13}$ In the current case, the patient had recurrent and severe anemia without evidence of gross GI bleeding, and the purplish stalked mass in the small bowel was diagnosed with capsule endoscopy. The 
mass was a solitary cavernous hemangioma, which is seldom identified with the usual methods such as CT or upper and lower GI endoscopy.

Internationally, there have been about five cases of solitary cavernous hemangioma of the small bowel along with long-standing iron-deficiency anemia and no gross GI bleeding. ${ }^{1,2,6,8,14}$ Three of the five cases developed in children, ${ }^{1,8,14}$ and two of these three cases showed the same clinical manifestation and were diagnosed with capsule endoscopy as in this case. ${ }^{1,14}$ One of these three cases showed the same clinical features as this case, but it was diagnosed with Technetium- $99 \mathrm{~m}$ red blood cell scintigraphy. ${ }^{8}$ Only two cases of cavernous hemangioma of the small bowel have been reported domestically. Kye et al..$^{15}$ reported of an 81-year-old female patient who presented with nausea, dizziness, and intermittent melena for three months; in this case, a mass in the small bowel was diagnosed with CT. She had undergone an explorative laparotomy, and histology revealed a cavernous hemangioma. Park ${ }^{11}$ performed explorative laparotomy on a 2-year-old boy with melena and severe iron-deficiency anemia since 18 months. He had been symptomatic with gross GI bleeding. The patient was likewise diagnosed with a small bowel cavernous hemangioma. The previously reported patient $\mathrm{s}^{11,15}$ developed overt GI bleeding and they were treated by utilizing different diagnostic techniques than the presented case.

Small bowel lesions can be detected at similar success rates with capsule endoscopy and double-balloon endoscopy. ${ }^{9}$ Double-balloon enteroscopy is a sensitive diagnostic tool. ${ }^{16}$ Although the procedure is a useful method for diagnosis, it is more suited for adult patients with small bowel abnormalities than for children, as the outer diameter of the double-balloon enteroscope is $12.2 \mathrm{~mm}$, which could be very uncomfortable for children. Complications of the method, including postprocedural abdominal pain, GI tract tears, and acute pancreatitis, have been reported in children. ${ }^{16}$ However, capsule endoscopy helps to identify the leading causes of obscure GI bleeding in all age groups. ${ }^{9,17-19}$

Capsule endoscopy is superior to push enteroscopy and small bowel barium radiography for the diagnosis of clinically significant small bowel pathologies in patients with obscure GI bleeding. ${ }^{7}$ When patients have recurrent and severe anemia with no evidence of gross bleeding, obscure GI bleeding of the small bowel should be considered in the differential diagnosis. ${ }^{9,17,20}$

In conclusion, capsule endoscopy may be a reasonable alternative diagnostic tool for small hemangiomas with chronic GI blood loss among children, especially in those with accompanying diseases that are difficult to differentiate, as reported in the present case.

\section{Conflicts of Interest}

The authors have no financial conflicts of interest.

\section{REFERENCES}

1. Magnano A, Privitera A, Calogero G, Nanfito L, Basile G, Sanfilippo G. Solitary hemangioma of the small intestine: an unusual cause of bleeding diagnosed at capsule endoscopy. J Pediatr Surg 2005;40:e25-e27.

2. Huber A, Abdel Samie A, Kychenko D, Theilmann L. A rare cause of recurrent iron-deficiency anemia: cavernous hemangioma of the small intestine. J Gastrointestin Liver Dis 2012;21:343.

3. Handra-Luca A, Montgomery E. Vascular malformations and hemangiolymphangiomas of the gastrointestinal tract: morphological features and clinical impact. Int J Clin Exp Pathol 2011;4:430-443.

4. Morgan DR, Mylankal K, el Barghouti N, Dixon MF. Small bowel haemangioma with local lymph node involvement presenting as intussusception. J Clin Pathol 2000;53:552-553.

5. Willert RP, Chong AK. Multiple cavernous hemangiomas with iron deficiency anemia successfully treated with double-balloon enteroscopy. Gastrointest Endosc 2008;67:765-767.

6. Chen $\mathrm{CH}$, Jones J, McGowan P. Profound iron deficiency anemia caused by a small-intestinal cavernous hemangioma. Gastrointest Endosc 2009;69:1392-1393.

7. Triester SL, Leighton JA, Leontiadis GI, et al. A meta-analysis of the yield of capsule endoscopy compared to other diagnostic modalities in patients with obscure gastrointestinal bleeding. Am J Gastroenterol 2005;100:2407-2418.

8. Sakaguchi M, Sue K, Etoh G, et al. A case of solitary cavernous hemangioma of the small intestine with recurrent clinical anemic attacks in childhood. J Pediatr Gastroenterol Nutr 1998;27:342-343.

9. Watari I, Oka S, Tanaka S, et al. Is occult obscure gastrointestinal bleeding a definite indication for capsule endoscopy? A retrospective analysis of diagnostic yield in patients with occult versus overt bleeding. Gastroenterol Res Pract 2013;2013:915463.

10. Hartmann D, Schmidt H, Bolz G, et al. A prospective two-center study comparing wireless capsule endoscopy with intraoperative enteroscopy in patients with obscure GI bleeding. Gastrointest Endosc 2005;61:826832.

11. Park J. Large cavernous hemangioma in the jejunum of a 2-year-old boy treated by laparoscopy-assisted resection. J Korean Assoc Pediatr Surg 2012;18:24-29.

12. Raju GS, Gerson L, Das A, Lewis B; American Gastroenterological Association. American Gastroenterological Association (AGA) Institute technical review on obscure gastrointestinal bleeding. Gastroenterology 2007;133:1697-1717.

13. Goddard AF, James MW, McIntyre AS, Scott BB; British Society of Gastroenterology. Guidelines for the management of iron deficiency anaemia. Gut 2011;60:1309-1316.

14. Pera M, Marquez L, Dedeu JM, et al. Solitary cavernous hemangioma of the small intestine as the cause of long-standing iron deficiency anemia. J Gastrointest Surg 2012;16:2288-2290.

15. Kye BH, Kim SH, Lee JI, et al. Hemorrhage from a jejunal polypoid hemangioma: single incisional laparoscopic approach. J Korean Surg Soc 2011;80:362-366.

16. Liu W, Xu C, Zhong J. The diagnostic value of double-balloon enteroscopy in children with small bowel disease: report of 31 cases. Can J Gastroenterol 2009;23:635-638.

17. Oikawa-Kawamoto M, Sogo T, Yamaguchi T, et al. Safety and utility of capsule endoscopy for infants and young children. World J Gastroenterol 2013;19:8342-8348.

18. Bar-Meir S, Eliakim R, Nadler M, et al. Second capsule endoscopy for patients with severe iron deficiency anemia. Gastrointest Endosc 2004;60:711-713. 


\section{$C_{\text {cunwca enooscopy }}$}

19. Zhang BL, Chen CX, Li YM. Capsule endoscopy examination identifies different leading causes of obscure gastrointestinal bleeding in patients of different ages. Turk J Gastroenterol 2012;23:220-225.
20. Tong J, Svarta S, Ou G, Kwok R, Law J, Enns R. Diagnostic yield of capsule endoscopy in the setting of iron deficiency anemia without evidence of gastrointestinal bleeding. Can J Gastroenterol 2012;26:687-690. 